\title{
A Case of Pleomorphic Post Kala-azar Dermal Leishmaniasis without History of Visceral Leishmanniasis
}

\section{Dipankar Pal ${ }^{1 *}$, Manoj Kumar Gupta ${ }^{1}$, Tamalika Das ${ }^{1}$ and Shristi Butta ${ }^{2}$}

${ }^{1}$ School of Tropical Medicine, 108, Chittaranjan Avenue, Kolkata-700073, West Bengal, India

2Department of Pathology, NRS Medical College, 138 AJC Bose Road, Kolkata-700014, West Bengal, India

"Corresponding author: Dipankar Pal, RMO cum Clinical Tutor, Department of Tropical Medicine, School of Tropical Medicine, 108, Chittaranjan Avenue, Kolkata-700073, West Bengal, India, Tel: +91-9432113713; E-mail: dipankarpal.2009@gmail.com

Received date: September 9, 2015, Accepted date: September 12, 2015, Published date: September 16, 2015

Copyright: (c) 2015 Pal et al. This is an open-access article distributed under the terms of the Creative Commons Attribution License, which permits unrestricted use, distribution, and reproduction in any medium, provided the original author and source are credited.

\section{Introduction}

Post kala-azar dermal leishmaniasis (PKDL) is a complication of visceral leishmaniasis (VL). It is characterised by macular, maculopapular and/or nodular lesions in a patient who has recovered from VL. It is commoner in Sudan where it follows as much as $50 \%$ of treated VL cases, whereas the figure is only $5-10 \%$ in India. [1].

PKDL probably has an important role in interepidemic periods of $\mathrm{VL}$ in maintaining the parasite reservoir [1]. There is increasing evidence that its pathogenesis is largely immunologically mediated. Diagnosis is mainly clinical, but parasites can be seen in tissue biopsy with limited sensitivity. PCR and monoclonal antibodies may detect parasites in more than $80 \%$ of cases [2]. Indian PKDL should always be treated whereas in the Sudanese variety, spontaneous cure is the rule [1]. Treatment is required only in severe and chronic cases in Sudan.

\section{Case Proper}

A 42 years old male farmer from rural West Bengal presented to us with hypopigmented macules, nodules and plaques in different parts of the body including face, hands, trunk and both feet for the last 10 months (Figures 1 and 2).

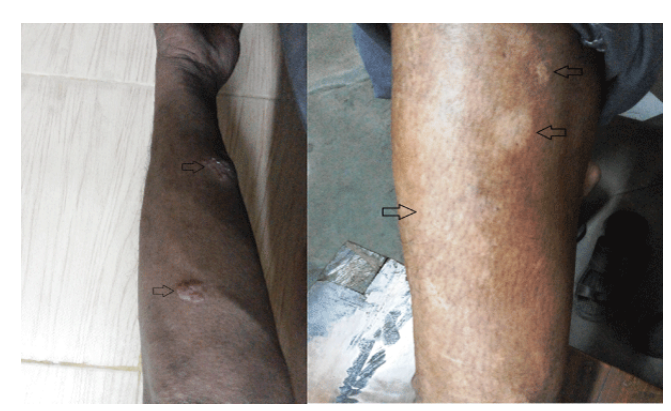

Figure 1: Showing maculo papular lesions over the forearm and leg (arrow).

Some of the nodules have central ulceration (Figure 3). Otherwise the lesions were painless, non-pruritic but progressive in nature. There was no history of Kala-azar previously. He was treated with antileprotic medicines for 6 months from the time of diagnosis. But his lesions didn't show any improvement despite treatment. We performed a skin biopsy from the edge of the lesion which showed both intracellular and extra cellular LD bodies. Miltefosine $50 \mathrm{mg}$ twice a day was started and he is now under our supervision for response.

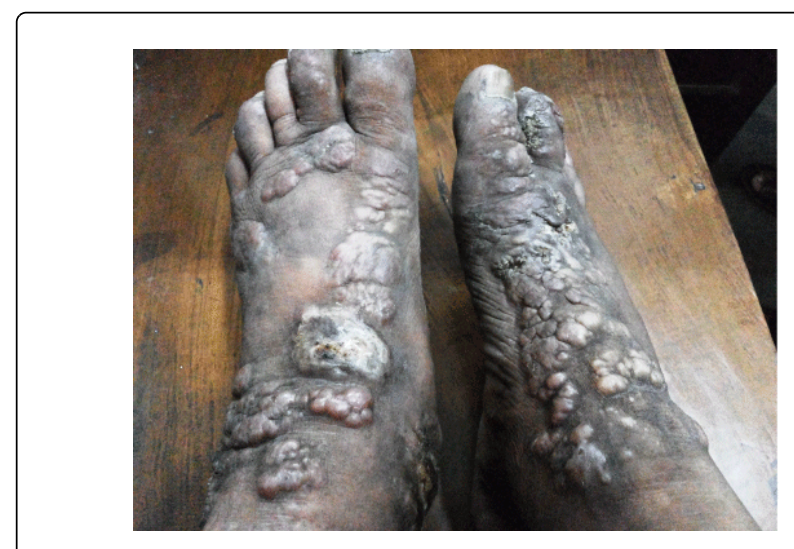

Figure 2: Showing nodulo ulcerative lesions over both the feet.

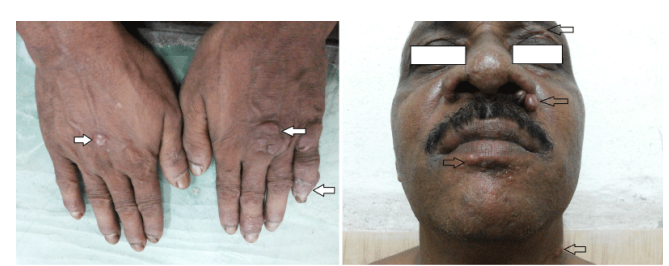

Figure 3: Nodular and plaque type lesions over hands and face (arrow).

\section{Discussion}

PKDL is a known complication of VL, and it occurs in patients successfully treated for VL. Very rarely it can develop without previous history of visceral disease [3]. On extensive literature search no case of primary PKDL without treatment of VL is found. Moreover, pleomorphic PKDL with macules, papules and nodules in different parts of body in the same patient is also very rare. Pal et al. in their case report has demonstrated such a case which was responsive to standard dose of miltefosine [4].

\section{Conclusion}

Post kala-azar dermal leishmaniasis (PKDL) is an important factor in kala-azar transmission in the community; hence its early detection, assessment and effective treatment is very important to reduce disease spread. 
Citation: Pal D, Manoj KG, Das T, Shristi B (2015) A Case of Pleomorphic Post Kala-azar Dermal Leishmaniasis without History of Visceral Leishmanniasis. Trop Med Surg 3: I103. doi:10.4172/2329-9088.1000I103

Page 2 of 2

\section{References}

1. Zijlstra EE, Musa AM, Khalil EA, el-Hassan IM, el-Hassan AM (2003) Post kala-azar dermal leishmaniasis. Lancet Infect Dis 3: 87-98.

2. Salotra P, Singh R (2006) Challenges in the diagnosis of post kala-azar dermal leishmaniasis. Indian J Med Res 123: 295-310.
3. el-Hassan AM, Ghalib HW, Zylstra E, Eltoum IA, Ali MS, et al. (1990) Post kala-azar dermal leishmaniasis in the absence of active visceral leishmaniasis. Lancet 336: 750.

4. Pal D, Naskar A, Ghosh MK (2013) A case of miltefosine responsive pleomorphic post kala-azar dermal leishmaniasis. Braz J Infect Dis 17: 610-612. 